\title{
Diferenciais Compensatórios de Salário para Trabalhadores com Preferências Heterogêneas: Evidências para o Caso Brasileiro
}

\section{Compensating Wage Differentials for Workers with Heterogeneous Preferences: Evidences for Brazil}

\author{
Aléssio Tony Cavalcanti Almeida \\ Ignácio Tavares Araújo Júnior ${ }^{a}$
}

\begin{abstract}
Resumo: Este artigo estuda como preferências heterogêneas por trabalhos arriscados, captadas pelo tabagismo, estão relacionadas com o trade-off envolvendo a relação salário-risco. Com esse propósito, o modelo teórico desenvolvido por Viscusi e Hersch (2001) é testado para o caso brasileiro por meio dos dados da Pesquisa Especial de Tabagismo, integrante da Pesquisa Nacional por Amostra de Domicílios de 2008 (IBGE, 2009), e do Anuário Estatístico de Acidentes do Trabalho de 2008 (MPS, 2009). As estimativas são feitas por modelos empíricos condicionados para a média e por quantil da distribuição condicional de rendimentos, com controle para viés de seleção amostral e endogeneidade. Os principais achados indicam que os fumantes recebem um menor prêmio ao risco no comparativo ao recebido pelos não fumantes nas atividades econômicas com maior incidência de acidentes do trabalho não fatais. Conforme essas estimativas, o valor estatístico de um acidente do trabalho por ano é, na mediana para os não fumantes, de aproximadamente $R \$ 6,2$ mil por acidente e $R \$ 3,9$ mil para os fumantes, com diferenças também nesses valores nos outros quantis da distribuição condicional do salário.
\end{abstract}

Palavras-chave: preferências de risco; tabagismo; acidentes do trabalho.

Abstract: This paper studies how heterogeneous preferences for risky jobs, captured by smoking, are related to the trade-off involving wage-risk relationship. To reach this goal, the theoretical model developed by Viscusi e Hersch (2001) is tested for the Brazilian case from the data of the Special Smoking Survey (PETab) included in the National Survey by Household Sample (PNAD) 2008 (IBGE, 2009) and Yearbook Statistics of Job Injuries (AEAT) 2008 (MPS, 2009). Estimates are made by empirical models conditioned for the mean and quantile controling for problems of sample selection bias and endogeneity. The results show that smokers receive a lower risk premium than nonsmokers in economic activities with higher incidence of nonfatal occupational injuries. According to these estimates, the value of a statistical injury (VSI) per year is, on average, for non-smokers approximately $R \$ 6,200$ per injury and $R \$ 3,900$ for smokers, with 
differences also in the other quantiles of the conditional wage distribution.

Keywords: risk preferences; smoking; job injuries.

JEL Classification: I12; J24.

\section{Introdução}

A teoria dos preços hedônicos aponta que o nível de utilidade dos trabalhadores é positivamente relacionado com a taxa de salário. Existem, ainda, fatores específicos ao desenvolvimento das atividades ocupacionais, tais como insalubridade e probabilidade de acidentes que exercem influência na oferta e na demanda (VISCUSI, 1978; SMITH, 1979; VISCUSI; MOORE, 1987). Segundo Smith (1979), essa teoria explica que uma parte das diferenças salariais deve-se às condições indesejáveis dos tipos de trabalhos. Quanto maior o risco de acidentes do trabalho, maior deveria ser o salário da ocupação, sendo o prêmio a esse risco mensurado basicamente pelos diferenciais compensatórios de salário.

Como destacam Viscusi e Aldy (2003), regulações específicas para o mercado de trabalho que levam em conta imperfeições como insalubridade e risco de morte devem ser baseadas em medidas monetárias, como o valor estatístico de uma vida (value of a statistical life - VSL), que pode refletir o trade-off entre salário e risco enfrentados por trabalhadores expostos a situações de risco em suas atividades laborais. Tais medidas são úteis, pois permitem avaliar os custos e os benefícios de eventuais intervenções no mercado de trabalho com o propósito de lidar com as falhas citadas. A literatura empírica da área vem desenvolvendo análises sobre os diferenciais compensatórios de salários devidos às atividades laborais arriscadas com registros de estudos para países desenvolvidos e em desenvolvimento (VISCUSI; MOORE, 1987; HERSCH, 1998; VISCUSI; ALDY, 2003; ESTEVES, 2008; EVANS; SCHAUR, 2010; CONTZEN; WON; LAVIN, 2013). Nessa direção, Viscusi e Aldy (2003) fazem uma meta-análise dos trabalhos empíricos para diferentes países sobre o trade-off entre salário e risco e evidenciam a existência de diferenciais compensatórios tanto em ocupações passíveis de acidentes fatais quanto não fatais. Os autores mostram que, para o mercado de trabalho norte-americano, o VSL varia, conforme as especificações e amostras utilizadas, entre US\$ 4 milhões e US\$ 9 milhões.

Viscusi e Aldy (2003) salientam também a importância das estimativas do valor estatístico de um acidente não fatal (value of a statistical injury - VSI) como um controle estratégico para as políticas de preservação da segurança da integridade do trabalhador. Para os Estados Unidos, conforme a meta-análise dos citados autores, o VSI situa-se entre US\$20 mil e US\$ 70 mil ao ano. Destaca-se que, 
para o caso do Brasil, as pesquisas sobre os diferenciais compensatórios ainda são escassas. Nessa direção, os achados de Esteves (2008), por exemplo, ratificam a hipótese da compensação salarial em função de acidentes do trabalho na indústria manufatureira.

A maior parte das pesquisas empíricas sobre esse tema admite que os trabalhadores possuem preferências homogêneas frente ao risco de acidentes do trabalho. Como salientam Hersch e Viscusi (1990), Levine et al. (1997) e Munasinghe e Sicherman (2006), a taxa de desconto usada para a formação das preferências intertemporais dos indivíduos é fundamental para a decisão da escolha ocupacional. Integrando essa hipótese à teoria de salários hedônicos, Viscusi e Hersch (2001) desenvolvem um modelo teórico que prediz que trabalhadores com uma maior taxa de desconto intertemporal (representados por indivíduos fumantes) selecionam trabalhos com maior nível de risco do que os não fumantes.

Assim, os fumantes, que revelam uma maior predisposição em assumir ações de risco à saúde, auferem taxas de compensações salariais para atividades insalubres inferiores às recebidas pelos não fumantes. Para um mesmo background individual, os usuários do cigarro escolhem um ponto sobre a curva de oferta que reflete um menor salário requerido para um determinado patamar de risco, devido à subestimação dos perigos de acidentes do trabalho (HERSCH; VISCUSI, 1990; VISCUSI; HERSCH, 2001). No tocante aos resultados da modelagem sobre diferenciais compensatórios salariais para ocupações insalubres, Viscusi e Hersch (2001) mostram que fumantes estão dispostos a ganhar metade do prêmio ao risco de acidentes do trabalho estimado para os não fumantes.

Com a finalidade de investigar empiricamente as predições de Hersch e Viscusi (1990) e Viscusi e Hersch (2001), este artigo analisa a diferenciação compensatória salarial para atividades com maiores índices de acidentes não fatais do trabalho entre fumantes e não fumantes no Brasil. Essa avaliação possibilita compreender como o fato do indivíduo ser usuário de cigarro na fase adulta repercute no trade-off envolvendo salário e risco de acidentes do trabalho. Além de indicar a maior predisposição de correr riscos no trabalho por parte dos fumantes, este estudo revela um potencial prejuízo salarial associado ao uso do cigarro, um efeito ainda pouco estudado na literatura nacional. Representando um avanço nos trabalhos empíricos sobre o tema, nesta pesquisa são usados estimadores quantílicos com controle para endogeneidade e viés de seleção para examinar as estimativas ao longo de diferentes pontos da distribuição condicional do salário-hora de trabalhadores brasileiros. Essa abordagem permite avaliar como os diferenciais compensatórios variam conforme a produtividade do trabalhador.

Além desta introdução, a pesquisa é composta por mais cinco partes. A seção 2 apresenta o modelo de Viscusi e Hersch (2001) sobre os diferenciais compensatórios para agentes com preferências heterogêneas, bem como faz uma breve exposi- 
ção dos resultados empíricos da área. As seções 3 e 4 detalham o modelo empírico e a base de dados utilizados para o desenvolvimento da presente pesquisa. Ao final, as seções 5 e 6 apresentam os principais resultados e as considerações finais.

\section{Modelo Teórico}

Para Smith (1979), a taxa de salário contém uma série de elementos relevantes para a tomada de decisão para os lados da oferta e demanda do mercado de trabalho, a saber: intensidade do trabalho, probabilidade de acidente, tarefas insalubres ou que geram desutilidade, etc. Sob os fundamentos da teoria dos salários hedônicos, ${ }^{1}$ a utilidade do trabalhador é crescente com a taxa de salário $(w)$ e decrescente com os indicadores de risco de acidentes do trabalho fatais ( $r$ ) e não fatais $(p)$. Com efeito, incorpora os preços implícitos desses riscos atrelados ao exercício do emprego, denominados de diferenciais compensatórios, $w^{\prime}(p)=\partial w / \partial p$ ou $w^{\prime}(r)=\partial w / \partial r$ que correspondem à inclinação da curva do salário hedônico.

Tratando do risco de acidentes não fatais do trabalho, $w^{\prime}(p)$ representa, na margem, o VSI. ${ }^{2} \mathrm{O}$ VSL é específico para os casos de riscos de acidentes fatais, sendo representado por $w^{\prime}(r)$. Essas medidas são comumente utilizadas na literatura para expressar o pagamento adicional que os trabalhadores esperam pela periculosidade do trabalho. Viscusi e Aldy (2003), que fazem uma revisão dessa literatura nos últimos 30 anos, confirmam a hipótese de diferenciais salariais para compensar os riscos ocupacionais para diferentes tipos de modelagens econométricas numa série de países. ${ }^{3}$ Os autores identificam ao longo dos diversos trabalhos empíricos para os Estados Unidos que, na mediana, o VSL anual equivale a US\$ 7 milhões de dólares. Por outro lado, em países em desenvolvimento, o VSL é bem inferior do que o estimado nas localidades mais desenvolvidas, sinalizando uma maior sensibilidade das curvas de salários hedônicos em economias com maior nível de renda per capita. Quanto ao VSI, os valores estimados, a preços constantes do ano 2000 para o mercado de trabalho dos Estados Unidos, se situam entre US\$ 20 mil e US $\$ 70$ mil.

Nesse contexto, o trabalho de Hersch e Viscusi (1990) explora até que ponto a adoção de hábitos pessoais que revelam atitudes ao risco (como o uso do cinto de segurança e de cigarro) podem refletir no trade-off salário-risco. Os achados para trabalhadores norte-americanos explicitam que os hábitos pessoais relacionados à saúde determinam a taxa de compensação requerida para atividades arris-

1 A teoria dos salários hedônicos presume conceitos estabelecidos pela teoria dos preços hedônicos apresentada por Rosen (1974).

2 "Valor estatístico de um acidente" é a tradução desse termo adotada nesta pesquisa.

3 Esteves (2008), usando dados da Relação Anual de Informações Sociais (Rais) e do AEAT/MPS, de 1997 a 1999, direcionados para trabalhadores formais, explicita a existência de diferenciais compensatórios para o Brasil. 
cadas, com os fumantes tendendo a subestimar os riscos (recebendo, em média, uma menor taxa de compensação salarial por unidade de risco do trabalho) e os indivíduos que revelam menor aversão ao risco requerendo uma maior compensação para atividades mais arriscadas.

Viscusi e Hersch (2001) desenvolvem um modelo alicerçado nas hipóteses de Hersch e Viscusi (1990), em que as preferências pessoais de risco à saúde dos trabalhadores são associadas com a taxa de salário de compensação e à escolha ocupacional dos agentes. Trabalhadores fumantes e não fumantes são divididos em grupos com preferências ao risco distintas quando se considera o loci salário-risco (como exibido na Figura 1). Destarte, os usuários do cigarro revelam atitudes e predisposição ao risco, pois, por exemplo, o consumo de cigarro gera uma menor expectativa de vida e sinaliza que o indivíduo possui uma maior taxa de desconto intertemporal com respeito aos seus anos de vida (HERSCH; VISCUSI, 1990; VISCUSI; HERSCH, 2001; SCHARFF; VISCUSI, 2011).

O modelo sobre tabagismo e diferenciação compensatória incorpora o papel do status de fumante nos dois lados do mercado, com o propósito de avaliar o papel das preferências de risco usando a condição de fumante como um indicador de atitudes em face ao risco. A taxa de salário, o prêmio ao risco e os riscos de acidentes do trabalho são denotados, respectivamente, por $w, \mathrm{w}_{p}$ e $p$, com $0 \leq p \leq 1$ e $w_{p}>0$ e, pois existe um custo marginal positivo para a segurança do trabalho. Admitem-se dois tipos de função utilidade: $U_{1}[w(p, s)]$, que reflete a utilidade para boas condições de saúde; e $U_{2}[w(p, s), h(s)]$, para o caso da utilidade em condições de acidentado. Nesse caso, representa a intensidade com a qual o indivíduo utiliza cigarro (se s $=0$, tem-se que o indivíduo é não fumante) e $h$ (s) é um índice de utilidade não observável, que capta uma maior disposição para assumir riscos à saúde. Desse modo, o problema de otimização é estabelecido pela equação 1:

$$
\max _{p} V=(1-p) U_{1}[w(p, s)]+p U_{2}[w(p, s) h(s)]
$$

Pela condição de primeira ordem $\left(\frac{\partial V}{\partial p}=0\right)$, obtém-se o valor referente ao diferencial compensatório $w_{p}=\frac{\partial w(p, s)}{\partial p}$ exposto na equação 2 :

$$
w_{p}=\frac{U_{1}[w(p, s)]-U_{2}[w(p, s) h(s)]}{(1-p) \frac{\partial U_{1}[w(p, s)]}{\partial w(p, s)}+p \frac{\partial U_{2}[w(p, s) h(s)]}{\partial w(p, s)}} .
$$

Pela equação 2, as escolhas dos agentes dependem da estrutura das funções de utilidade e das curvas de oferta de salários. Para se medir o efeito da intensi- 
dade do uso do cigarro no ponto ótimo do trabalho de risco selecionado, faz-se a diferenciação total da equação 2 , resolvendo para $\frac{\partial p}{\partial s}$ :

$$
\begin{aligned}
& \frac{\partial p}{\partial s}=\left[-\left(U_{1 w}-U_{2 w}\right) w_{s}+(1-p) U_{1 w w} w_{s} w_{p}+(1-p) U_{1 w} w_{p s}\right. \\
& \left.+U_{2 h} h_{s}+p U_{2 w w} w_{s} w_{p}+p U_{2 w h} w_{p} h_{s}+p U_{2 w} w_{p s}\right] \times(-D)^{-1},
\end{aligned}
$$

em que $D=-2 w_{p}\left(U_{1 w}-U_{2 w}+(1-p) U_{1 w w}\left(w_{p}\right)^{2}+(1-p) U_{1 w} w_{p p}+p U_{2 w} w_{p p}<0\right.$.

O sinal do efeito do cigarro no trade-off salário-risco é ditado, em especial, pelo sinal de $w_{\mathrm{ps}}$. Se $w_{\mathrm{ps}} \geq 0$, o salário de risco é ampliado com a intensidade do uso do cigarro. Caso contrário, $\frac{\partial p}{\partial s}$ pode ser negativo, desde que o efeito seja dominante. Dessa forma, Viscusi e Hersch (2001) destacam diferentes possibilidades envolvendo o efeito do tabagismo na diferenciação compensatória. Duas dessas possibilidades estão descritas na Figura 1.

Figura 1 - Relação salário-risco por status de fumante para dois casos hipotéticos

(a) Caso 1: $w_{s}<0, w_{p s}>0$

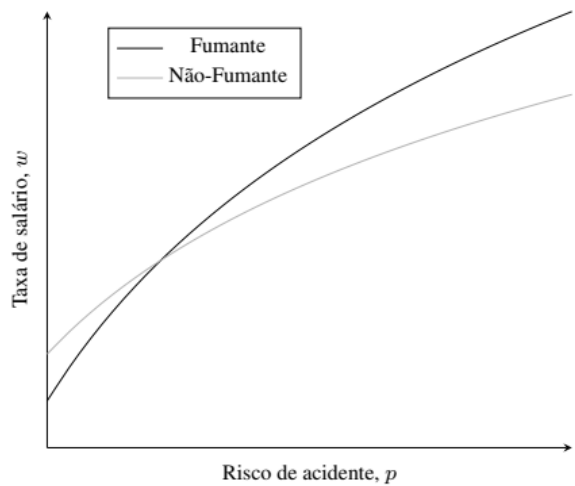

(b) Caso 2: $w_{s}<0, w_{p s}<0$

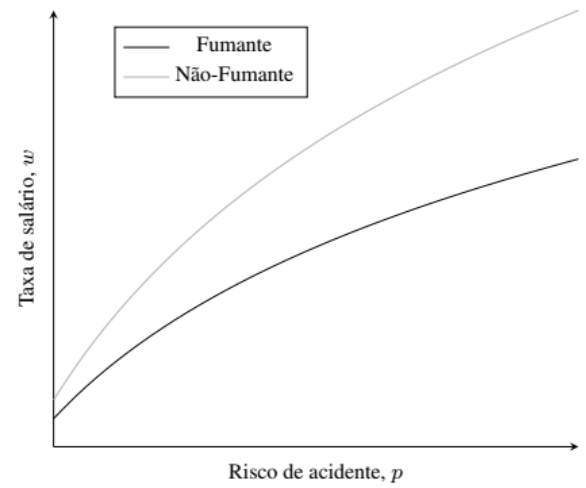

Fonte: Elaboração própria.

As evidências empíricas de Viscusi e Hersch (2001) - usando dados do National Medical Expenditure Survey (NMES), de 1987, e do Bureau of Labor Statistics (BLS), para uma amostra de 4.821 trabalhadores do sexo masculino, entre 18 e 65 anos de idade, dos Estados Unidos - sustentam a suposição que fumantes são mais propensos a selecionar trabalhos com maior probabilidade de acidentes e a receber salários de compensação para o risco inferiores aos recebidos pelos não fumantes. Segundo o estudo, conforme os valores implícitos por acidente, os fumantes recebem um valor esperado $56 \%$ menor do que o recebido pelos não fumantes. 
Acerca dos problemas empíricos de estimação do prêmio ao risco, Garen (1988) adverte que a endogeneidade do risco de acidentes causa viés nas estimativas, com a subestimação dos diferenciais compensatórios para riscos fatais e não fatais por mínimos quadrados ordinários (MQO). Além de Garen (1988), um conjunto de pesquisas, como as de Viscusi e Hersch (2001), Viscusi e Aldy (2003), Esteves (2008), Polat (2013) e Contzen, Won e Lavin (2013), ressalta o problema de endogeneidade mencionado e a maioria delas adota a abordagem de variáveis instrumentais para superar o problema. Basicamente, existem dois canais para o problema de endogeneidade: simultaneidade, visto que segurança é um bem normal, trabalhadores com mais riqueza tendem a optar por trabalhos mais seguros e existência de fatores não observados que exercem influência tanto na percepção de risco quanto na taxa de salário. Viscusi e Aldy (2003) relatam que o tratamento ideal dos fatores não observáveis, resultantes de diferenças nas características do trabalhador, seria por meio de dados longitudinais. Para tanto, o próprio autor admite a dificuldade desse tipo de investigação pela escassez de surveys que seguem um conjunto de indivíduos ao longo de vários anos que possuam medidas para o cômputo de condições insalubres de trabalho.

\section{Estratégia Empírica}

O modelo empírico descrito nesta parte toma por referência Garen (1988), Hersch e Viscusi (1990), Viscusi e Hersch (2001), Fernandez e Nordman (2009) e Contzen, Won e Lavin (2013). A equação 4, que capta o equilíbrio resultante do trade-off salário-risco comumente usada nessa literatura, ${ }^{4}$ é o ponto de partida para a avaliação dos diferenciais compensatórios salariais. Nessa expressão, inclui-se como covariada o indicador do nível de risco inerente ao desempenho de uma determinada atividade econômica, ${ }^{5}$ com regressões separadas entre fumantes $(f)$ e não fumantes ( $n f$ ), como no trabalho de Viscusi e Hersch (2001):

$$
\left\{\begin{array}{l}
W_{i j}^{f}=a_{0}^{f}+a_{1}^{f} \mathrm{p}_{i j}^{f}+\boldsymbol{X}_{i}^{f} \boldsymbol{\alpha}^{f}+\epsilon_{i j}^{f} \\
W_{i j}^{n f}=a_{0}^{n f}+a_{1}^{n f} \mathrm{p}_{i j}^{n f}+\boldsymbol{X}_{i}^{n f} \boldsymbol{\alpha}^{n f}+\epsilon_{i j}^{n f}
\end{array}\right.
$$

em que $p_{i j}$ é o índice de risco de acidentes do trabalho para o i-ésimo trabalhador empregado na divisão econômica j. Como adotado por Viscusi e Hersch

$4 \quad$ Ver Smith (1979), Arnould e Nichols (1983), Viscusi e Hersch (2001) e Fernandez e Nordman (2009).

5 Como salienta Fernandez e Nordman (2009), além dos benefícios pecuniários, existem outros prêmios não monetários associados às atividades mais arriscadas. 
(2001), Esteves (2008), Evans e Schaur (2010) e Contzen, Won e Lavin (2013), assume-se um efeito fixo dos indicadores de risco setorial de acidentes.

Para se mensurar o prêmio ao risco ( $w p$ ) entre fumantes e não fumantes, estima-se a expressão do salário hedônico do indivíduo $i$ em função dos seus atributos e de indicadores de risco da atividade j, considerando-se variáveis instrumentais que possam se correlacionar com a decisão dos indivíduos por atividades de risco e que não sejam relacionadas com o termo do erro. O exame do prêmio ao risco estimado para a função condicional média do salário, tal como desenvolvido por Hersch e Viscusi (1990), Viscusi e Hersch (2001), Esteves (2008) e Contzen, Won e Lavin (2013), não mede possíveis heterogeneidades entre os indivíduos, por exemplo, com baixa e alta produtividade, cujos diferenciais compensatórios podem ser diferentes (FERNANDEZ; NORDMAN, 2009; EVANS; SCHAUR, 2010).

Para se levar em conta essa heterogeneidade, as estimações para o prêmio de risco são realizadas para funções condicionais quantílicas da produtividade marginal do trabalho, usando-se a abordagem de estimadores quantílicos com regressores endógenos (RQVI) proposta por Chernozhukov e Hansen (2004, 2005, 2013) e Chernozhukov, Hansen e Jansson (2007). Os quantis 0,10 e 0,25 representam trabalhadores com baixo nível de produtividade marginal do trabalho e os quantis 0,75 e 0,90, os de alta produtividade. Como a variável de risco da indústria (p) é correlacionada com o termo de erro, as equações 5, 6 e 7 expressam a estimação dos diferenciais compensatórios salariais e dos determinantes da demanda dos trabalhadores por atividades arriscadas.

$$
\begin{gathered}
W_{i j}^{S}=a_{1}^{S}\left(E_{i}^{S}\right) p_{i j}^{S}+\boldsymbol{X}_{i}^{S} \boldsymbol{\alpha}^{S}\left(E_{i}^{S}\right), \operatorname{com} E_{i}^{S} \mid p_{i j}^{S}, \boldsymbol{X}_{i}^{S}, \boldsymbol{Z}_{i}^{S} \\
\sim \operatorname{uniforme}(0,1) \\
p_{i j}^{S}=f\left(\boldsymbol{X}_{i}^{S}, \boldsymbol{Z}_{i}^{S}, \Sigma_{i}^{S}\right) \\
\\
\tau \rightarrow a_{1}^{S}(\tau) p_{i j}^{S}+\boldsymbol{X}_{i}^{S} \boldsymbol{\alpha}^{S}(\tau)
\end{gathered}
$$

em que: $s=(f, n f) ; \Sigma_{i}^{s}$ é um vetor de variáveis omitidas correlacionadas com o termo de erro $E_{i} ; Z$ é o vetor de variáveis instrumentais baseado em Garen (1988), Timmins e Murdock (2007) e Contzen, Won e Lavin (2013) - composto por: tipo de família e existência de filhos no domicílio; dummy se o indivíduo é o chefe do domicílio; rendimento total do não trabalho; e cônjuge ou filhos com dificuldades físicas motivados por problemas de saúde. 
De acordo com a literatura da área, as equações auxiliares no modelo com VI relacionam inicialmente os níveis de perigo de acidentes no trabalho com indicadores observáveis sobre a percepção do nível de risco, que são correlacionados com o risco percebido dos acidentes, mas não explicam o salário recebido pelo indivíduo (GAREN, 1988). Para Contzen, Won e Lavin (2013), esse bloco inicial de instrumentos consiste em características individuais que captam a aversão ao risco, incluindo renda do não trabalho e alguns fatores que afetam a percepção de risco dos agentes, funcionando como proxies que mostram como os trabalhadores percebem os perigos de suas ocupações. Elas indicam o nível de maturidade do indivíduo quanto ao seu ciclo de vida e, assim, seu desejo por atividades mais seguras.

Cabe salientar, ainda, que os procedimentos de Buchinsky $(1998,2001)$ de correção pela aproximação da razão inversa de Mills serão empregados para a obtenção dos estimadores quantílicos para corrigir o viés de seleção amostral. Com isso, o salário observado $\left(S^{S}\right)$ dos dois grupos de indivíduos é estabelecido por: $S_{i j}^{S}=d_{i}^{s} \times W_{i j}^{s}$, com $d_{i}^{s}=I\left(W_{i j}^{s}>W_{i j}^{S R}\right)$, em que $I$ ( $\cdot$ )é uma função indicadora e $W_{i j}^{s}$ é observado se for maior que o salário de reserva $\left(W_{i j}^{s R}\right)$. Assim, $d_{i}^{s}=1$, caso o salário seja observável para o indivíduo $i$ com hábito $s$, e $d_{i}^{S}=0$, caso contrário.

Considerando-se tais procedimentos, inclui-se a aproximação da razão inversa de Mills com dois termos, ${ }^{6} h_{\tau}^{s}\left(g_{0}\right)$, no quantil condicional do salário observado, no qual $h_{\tau}^{S}\left(g_{0}^{S}\right)=Q_{\tau}\left(\epsilon_{i j}^{S} \mid p_{i j}^{S}, \boldsymbol{X}_{i}^{S}, \boldsymbol{Z}_{i}^{S}, d_{i}^{S}=1\right)$ e $g_{0}^{S}=g\left(\boldsymbol{J}_{i}^{S}, \boldsymbol{\kappa}_{0}^{S}\right)$. O vetor de variáveis explicativas, $J_{i}^{S}$, é formado por varáveis sobre a decisão de oferta do trabalho (com $\boldsymbol{X}^{s} \subset \boldsymbol{J}^{s}$ ), que são descritas na Tabela 3 no Apêndice A. Segundo Buchinsky (1998), a equação de participação na força de trabalho deve ser estimada por um modelo semiparamétrico, pois, na regresssão quantílica, a forma funcional dos erros tem formato desconhecido. Dessa maneira, a estimação da equação de participação é feita por meio do modelo de resposta binária de estimadores de máxima verossimilhança de Gallant e Nychka (1987), admitindo uma expansão polinomial univariada de terceira ordem de Hermite para fazer a aproximação da densidade desconhecida dos erros da regressão latente.

\section{Base de Dados e Descrição das Variáveis}

A Pesquisa Nacional por Amostra de Domicílios (PNAD) 2008, realizada pelo IBGE (2009), é a fonte de informações utilizada por dispor da Pesquisa Especial de Tabagismo (PETab) e de um suplemento sobre acesso e utilização dos serviços de saúde, condições de saúde do indivíduo e fatores de risco e proteção à saúde. Mais precisamente, os dados deste estudo compatibilizam os questionários da parte 27 da PNAD de 2008, menos detalhada, e da parte 28, mais minuciosa, sobre taba-

6 No caso dos modelos de referência para a função condicional média, o cálculo da razão inversa de Mills tradicional $(\lambda)$ usa o modelo probit para estimar a equação de participação. 
gismo. Ademais, foram utilizadas estatísticas de acidentes do trabalho ${ }^{7}$ do Anuário Estatístico de Acidentes de Trabalho de 2008 (AEAT; MPS, 2009) com informações sobre a maior quantidade de atividades econômicas possíveis.

Através da combinação entre a PNAD e o AEAT, o índice de risco de acidente do trabalho ${ }^{8}$ (Irat) é calculado para 54 divisões econômicas. As divisões com a maior incidência relativa de acidentes por 100 trabalhadores no período são: fabricação de máquinas para escritório e equipamentos de informática $(9,03)$; reciclagem (8,79); e fabricação de coque, refino de petróleo, elaboração de combustíveis e nucleares e produção de álcool $(4,40)$. Destaca-se que a amostra final usada na presente pesquisa inclui atividades com diferentes gradações de risco de acidentes (incluindo atividades com risco zero), conforme pode-se verificar na Figura 2, que apresenta a distribuição do Irat no país em 2008.

Figura 2 - Distribuição do índice de risco de acidente do trabalho: Brasil (2008)

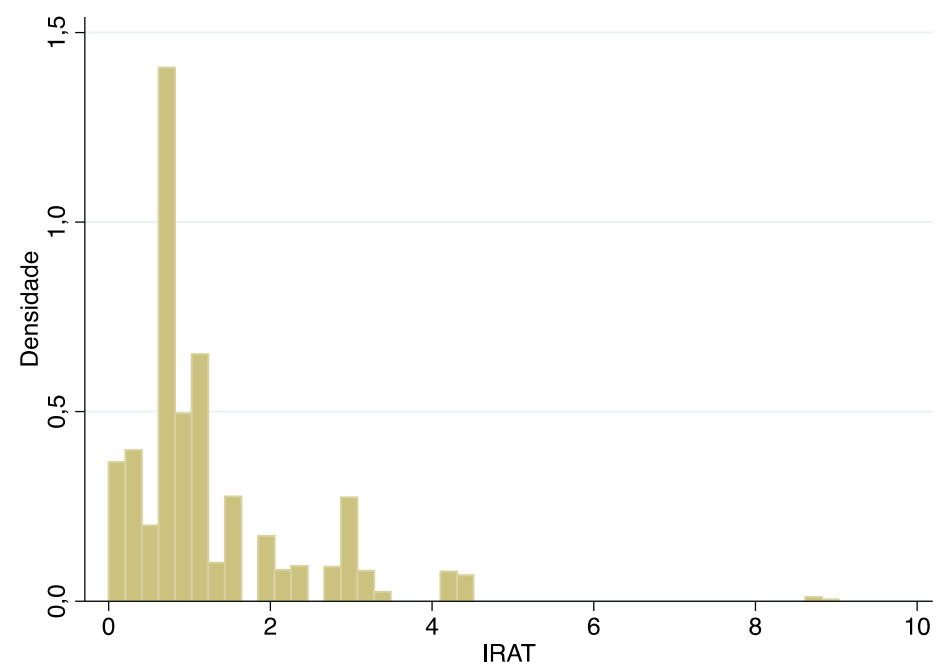

Fonte: Elaboração própria a partir dos microdados da PNAD/PETab 2008 e do AEAT/MPS 2008.

$7 \quad$ O total de acidentes do trabalho é composto por: acidentes com comunicações de acidentes do trabalho (CAT) registradas; acidentes sem CAT registradas; acidentes típicos, decorrentes das peculiaridades da atividade profissional; acidentes de trajeto; doença do trabalho, produzidas ou desencadeadas pelo exercício do trabalho relativo a determinado ramo de atividade.

8 Como o índice de risco de acidente de trabalho é dado pela relação entre a quantidade de acidentes e o número de ocupados em cada divisão econômica, as divisões com insuficiência amostral ( $\mathrm{n}<30$ ) ou com ou com falta de informações para compatibilização da Classificação Nacional de Atividades Econômicas (CNAE) domiciliar e com a CNAE 2.0 foram desconsideradas. 
Com os microdados da PNAD 2008, obtêm-se informações específicas sobre os usuários do cigarro, atributos pessoais, aspectos locacionais e indicadores do mercado de trabalho, bem como é possível particionar a amostra em três grupos de trabalhadores: fumantes correntes, ex-fumantes e indivíduos sem experiência com o cigarro. Dessa forma, para evitar contaminação no grupo de não fumantes, os ex-fumantes foram excluídos da amostra.

A exemplo de Viscusi e Hersch (2001), a amostra é restringida para trabalhadores do sexo masculino com nacionalidade brasileira e faixa etária entre 25 e 60 anos de idade. Além disso, aposentados e trabalhadores empregados no serviço público foram desconsiderados nessa análise. Para o caso dos servidores públicos, a produtividade do trabalho não implica em alterações na taxa de salário, bem como a estabilidade no emprego dificulta o cotejo desse grupo de trabalhadores com os empregados no setor privado. Para fins comparativos com os resultados de Viscusi e Hersch (2001), trabalhadores da agricultura e autônomos foram também suprimidos da amostra.

As seguintes variáveis explicativas são usadas nesta pesquisa: faixa de escolaridade (menos que ensino fundamental, fundamental completo, médio completo e superior completo), raça (cor branca), idade (em nível e ao quadrado), interação entre anos de estudo e idade do indivíduo, dummy se o trabalhador é sindicalizado, dummy se o trabalhador está ocupado em uma ocupação sem carteira assinada, estabilidade no emprego atual (tenure) e fatores locacionais (zona de localização, região metropolitana e macrorregiões de residência). Além delas, inclui-se o Irat como proxy para a probabilidade de ocorrência de danos à saúde do trabalhador em decorrência do exercício de seu trabalho. A Tabela 3 (ver Apêndice A) mostra a definição das variáveis utilizadas no estudo, inclusive as variáveis instrumentais e em qual modelagem são utilizadas. A Tabela 1 sumariza as estatísticas descritivas das variáveis utilizadas na estimação do modelo.

Tabela 1 - Estatísticas descritivas das variáveis utilizadas

\begin{tabular}{lcc|cc}
\hline \multirow{2}{*}{ Variáveis } & \multicolumn{2}{c|}{ Não fumante } & \multicolumn{2}{c}{ Fumante } \\
\cline { 2 - 5 } & Média & Desvio padrão & Média & Desvio padrão \\
\hline Salário-hora (em log) & 3,060 & 0,747 & 2,846 & 0,704 \\
Irat & 1,290 & 1,101 & 1,212 & 1,054 \\
Sindicalizado & 0,263 & 0,440 & 0,201 & 0,401 \\
Carteira assinada & 0,1792 & 0,3835 & 0,2955 & 0,4563 \\
\hline Grupos ocupacionais & & & & \\
\hline Dirigentes & 0,055 & 0,227 & 0,031 & 0,174 \\
Ciências e Artes & 0,079 & 0,270 & 0,041 & 0,199 \\
\hline Técnicos & 0,103 & 0,304 & 0,063 & 0,244 \\
Serviços administrativos & 0,099 & 0,299 & 0,067 & 0,249 \\
\hline
\end{tabular}

Continua... 
Conclusão.

\begin{tabular}{|c|c|c|c|c|}
\hline \multirow{2}{*}{ Variáveis } & \multicolumn{2}{|c|}{ Não fumante } & \multicolumn{2}{|r|}{ Fumante } \\
\hline & Média & Desvio padrão & Média & Desvio padrão \\
\hline Serviços* & 0,153 & 0,360 & 0,159 & 0,366 \\
\hline Vendedores & 0,070 & 0,255 & 0,055 & 0,228 \\
\hline Agrícola & 0,006 & 0,076 & 0,014 & 0,116 \\
\hline Produção e manutenção & 0,436 & 0,496 & 0,570 & 0,495 \\
\hline Estabilidade (tenure) & 5,906 & 6,452 & 5,488 & 6,871 \\
\hline \multicolumn{5}{|l|}{ Faixa de escolaridade } \\
\hline $\begin{array}{l}\text { Menos que ensino fundamental } \\
(<\mathrm{EF})\end{array}$ & 0,269 & 0,443 & 0,496 & 0,500 \\
\hline $\begin{array}{l}\text { Ensino fundamental completo } \\
(<\mathrm{EM})\end{array}$ & 0,181 & 0,385 & 0,189 & 0,392 \\
\hline Ensino médio completo $(<\mathrm{ES})$ & 0,421 & 0,494 & 0,253 & 0,435 \\
\hline Ensino superior completo* (ES) & 0,129 & 0,335 & 0,062 & 0,242 \\
\hline Raça & 0,511 & 0,500 & 0,483 & 0,500 \\
\hline Idade & 35,757 & 8,339 & 38,542 & 9,229 \\
\hline Chefe do domicilio & 0,635 & 0,481 & 0,640 & 0,480 \\
\hline \multicolumn{5}{|l|}{ Tipo de família } \\
\hline Casado sem filho & 0,136 & 0,343 & 0,130 & 0,336 \\
\hline Casado com filho & 0,688 & 0,463 & 0,666 & 0,472 \\
\hline Tamanho da família & 3,507 & 1,333 & 3,590 & 1,466 \\
\hline \multicolumn{5}{|l|}{ Rendimento de outras fontes } \\
\hline Pensão (em log) & 0,020 & 0,360 & 0,046 & 0,529 \\
\hline Aluguel (em log) & 0,086 & 0,713 & 0,060 & 0,605 \\
\hline Outros (em log) & 0,095 & 0,693 & 0,100 & 0,703 \\
\hline Renda total não trabalho (em log) & 0,198 & 1,039 & 0,200 & 1,044 \\
\hline Urbana & 0,946 & 0,226 & 0,934 & 0,249 \\
\hline Região metropolitana & 0,380 & 0,485 & 0,389 & 0,488 \\
\hline \multicolumn{5}{|l|}{ Macrorregião } \\
\hline Norte & 0,063 & 0,243 & 0,070 & 0,256 \\
\hline Nordeste & 0,211 & 0,408 & 0,178 & 0,383 \\
\hline Sudeste* & 0,514 & 0,500 & 0,506 & 0,500 \\
\hline Sul & 0,142 & 0,349 & 0,176 & 0,381 \\
\hline Centro-Oeste & 0,070 & 0,255 & 0,069 & 0,254 \\
\hline Controle: ex-fumantes & \multicolumn{2}{|r|}{$\mathrm{X}$} & \multicolumn{2}{|r|}{$\mathrm{X}$} \\
\hline Observações $(N)$ & \multicolumn{2}{|r|}{22.088} & \multicolumn{2}{|r|}{8.153} \\
\hline Observações expandidas $(P)$ & \multicolumn{2}{|r|}{10.739 .467} & \multicolumn{2}{|r|}{4.080 .790} \\
\hline
\end{tabular}

Fonte: Elaboração própria a partir dos microdados da PNAD/PETab 2008 e do AEAT/MPS 2008. 
Pela Tabela 1, em que os indivíduos ex-usuários do cigarro são excluídos da amostra, verifica-se que os perfis dos fumantes e não fumantes no país possuem algumas diferenças marcantes, sobretudo em termos de rendimento do trabalho, escolaridade e distribuição ocupacional. A média de idade dos trabalhadores não fumantes é de 36 anos e dos fumantes de 39 anos, com os primeiros apresentando maiores níveis do log dos salários e com uma menor concentração de indivíduos com menor faixa de escolaridade. A maior parte dos indivíduos da amostra está localizada nas regiões Sudeste, Nordeste e Sul.

\section{Resultados}

Esta seção testa a proposição do modelo de Viscusi e Hersch (2001) de diferenciais compensatórios de salários entre fumantes e não fumantes ao examinar a relação desse grupo de trabalhadores com as atividades de maior periculosidade de acidentes. A Tabela 2 exibe as estimativas para o parâmetro $a_{1}^{s}$ relativo aos riscos de acidentes - que representa o prêmio ao risco $\left(w_{p}=\partial w / \partial p\right)-$, com especificação econométrica aplicada separadamente por status de fumante para modelos sem e com VI.

Tabela 2 - Coeficiente do prêmio ao risco de acidentes do trabalho e VSI no Brasil por status de fumante e diferentes modelagens econométricas (2008)

\begin{tabular}{|c|c|c|c|c|c|c|}
\hline Especificações & Média & Mediana & $Q(0,10)$ & $\mathbf{Q}(0,25)$ & $\mathbf{Q}(0,75)$ & $\mathbf{Q}(0,90)$ \\
\hline & \multicolumn{6}{|c|}{ Não fumantes } \\
\hline \multicolumn{7}{|l|}{ Sem VI } \\
\hline Coeficiente $\left(w_{p}\right)$ & $0,0452 * * *$ & $0,0481 * * *$ & $0,0401 * * *$ & $0,0471^{* * *}$ & $0,0418^{* * *}$ & $0,0373 * * *$ \\
\hline Erro padrão & 0,0040 & 0,0033 & 0,0038 & 0,0033 & 0,0048 & 0,0061 \\
\hline VSI (em R \$ de 2008) & $1.929,43$ & $1.963,42$ & 912,67 & $1.397,78$ & $2.446,50$ & $3.140,97$ \\
\hline VSI (em US\$ de 2000) & 610,40 & 621,15 & 288,73 & 442,20 & 773,98 & 993,68 \\
\hline$R^{2}$ ajustado/ pseudo $R^{2}$ & 0,46 & 0,29 & 0,18 & 0,22 & 0,33 & 0,34 \\
\hline \multicolumn{7}{|l|}{ Com VI } \\
\hline Coeficiente $\left(w_{p}\right)$ & $0,1515^{* * *}$ & $0,1601 * * *$ & $0,1504^{* * *}$ & $0,1806^{* * *}$ & $0,2183^{* * *}$ & $0,1909^{* * *}$ \\
\hline Erro padrão & 0,0122 & 0,0147 & 0,0096 & 0,0113 & 0,0290 & 0,0319 \\
\hline VSI (em R\$ de 2008) & $6.462,27$ & $6.189,38$ & $3.308,63$ & $5.061,47$ & $12.453,97$ & $16.303,74$ \\
\hline VSI (em US\$ de 2000) & $2.044,41$ & $1.958,08$ & $1.046,72$ & $1.601,25$ & $3.939,95$ & $5.157,87$ \\
\hline$R^{2}$ ajustado & 0,44 & $\mathrm{n} / \mathrm{d}$ & $\mathrm{n} / \mathrm{d}$ & $\mathrm{n} / \mathrm{d}$ & $\mathrm{n} / \mathrm{d}$ & $\mathrm{n} / \mathrm{d}$ \\
\hline$N$ & 22.088 & 22.088 & 22.088 & 22.088 & 22.088 & 22.088 \\
\hline
\end{tabular}

Continua... 
Conclusão.

\begin{tabular}{|c|c|c|c|c|c|c|}
\hline Especificações & Média & Mediana & $\mathbf{Q}(0,10)$ & $\mathbf{Q}(0,25)$ & $\mathbf{Q}(0,75)$ & $\mathbf{Q}(0,90)$ \\
\hline \multirow[t]{2}{*}{$P$} & 10.739 .467 & 10.739 .467 & 10.739 .467 & 10.739 .467 & 10.739 .467 & 10.739 .467 \\
\hline & \multicolumn{6}{|c|}{ Fumantes } \\
\hline \multicolumn{7}{|l|}{ Sem VI } \\
\hline Coeficiente 0 & $0,0225 * * *$ & $0,0254^{* * *}$ & $0,0169^{* *}$ & $0,0174^{* * *}$ & $0,0153^{* * *}$ & $0,0296 * * *$ \\
\hline Erro padrão & 0,0065 & 0,0061 & 0,0066 & 0,0058 & 0,0056 & 0,0107 \\
\hline VSI (em R\$ de 2008) & 775,69 & 840,18 & 317,25 & 426,17 & 710,99 & $1.922,49$ \\
\hline VSI (em US\$ de 2000) & 245,40 & 265,80 & 100,37 & 134,82 & 224,93 & 608,20 \\
\hline$R^{2}$ ajustado & 0,44 & 0,25 & 0,16 & 0,18 & 0,28 & 0,35 \\
\hline \multicolumn{7}{|l|}{ Com VI } \\
\hline Coeficiente $\left(w_{p}\right)$ & $0,0996 * * *$ & $0,1054 * * *$ & $0,0469^{* * *}$ & $0,0800 * *$ & $0,1109^{* * *}$ & $0,1354^{* * *}$ \\
\hline Erro padrão & 0,0224 & 0,0222 & 0,0199 & 0,0368 & 0,0536 & 0,0330 \\
\hline VSI (em R\$ de 2008) & $3.431,28$ & $3.860,76$ & 957,21 & $2.221,98$ & $5.564,68$ & $9.519,86$ \\
\hline VSI (em US\$ de 2000) & $1.085,52$ & $1.221,39$ & 302,83 & 702,95 & $1.760,45$ & $3.011,71$ \\
\hline ajustado & 0,42 & $\mathrm{n} / \mathrm{d}$ & $\mathrm{n} / \mathrm{d}$ & $\mathrm{n} / \mathrm{d}$ & $\mathrm{n} / \mathrm{d}$ & $\mathrm{n} / \mathrm{d}$ \\
\hline$N$ & 8.153 & 8.153 & 8.153 & 8.153 & 8.153 & 8.153 \\
\hline$P$ & 4.080 .790 & 4.080 .790 & 4.080 .790 & 4.080 .790 & 4.080 .790 & 4.080 .790 \\
\hline Atributos individuais & $X$ & $X$ & $X$ & $X$ & $X$ & $X$ \\
\hline Fatores locacionais & $\mathrm{X}$ & $\mathrm{X}$ & $\mathrm{X}$ & $\mathrm{X}$ & $\mathrm{X}$ & $\mathrm{X}$ \\
\hline Controle: viés de seleção & $X$ & $\mathrm{X}$ & $\mathrm{X}$ & $X$ & $X$ & $X$ \\
\hline Controle: ex-fumantes & $X$ & $X$ & $\mathrm{X}$ & $\mathrm{X}$ & $\mathrm{X}$ & $X$ \\
\hline
\end{tabular}

Fonte: Elaboração própria a partir dos microdados da PNAD/PETab 2008 e do AEAT/MPS 2008.

Nota: Erros padrões robustos, corrigidos por correlação intragrupo e independência intergrupos; $\mathrm{n} / \mathrm{d}$ = não disponível; instrumentos: renda total do não trabalho, estrutura familiar (casado sem filhos e casado com filhos), chefe do domicilio, filho com dificuldades físicas e cônjuge com dificuldades físicas; os trabalhadores da agricultura e conta-própria foram desconsiderados da amostra para fins comparativos com os resultados de Viscusi e Hersch (2001); VSI computado supondo 2.000 horas de trabalho para anualização dos salários previstos; para a obtenção do VSI para dólares do ano 2000, fez-se a conversão dos valores em reais de 2008 para o ano 2000 por meio do Índice Nacional de Preços ao Consumidor Amplo (IPCA) e, em seguida, utilizou-se a taxa de câmbio real (R\$) por dólar (US\$) do ano 2000 disponível na plataforma Penn World Table (http://pwt.sas.upenn.edu) de Feenstra, Inklaar e Timmer (2013); * $p<0,10 ; * * p<0,05 ; * * p<0,01$.

O pressuposto de diferenciais compensatórios salariais é verificado se os coeficientes do prêmio ao risco de acidentes não fatais do trabalho $\left(w_{p}\right)$ forem estatisticamente significativos e maiores do que zero. Segundo a Tabela 2, o parâmetro $a_{1}^{s}$ apresenta sinal positivo e é estatisticamente significativo a 5\% de significância em todos os modelos para os dois grupos de trabalhadores. Todavia, as abordagens com variáveis instrumentais se diferenciam pela maior magnitude dos coeficientes. 
Essas evidências, acompanhando os trabalhos de Smith (1979), Viscusi e Moore (1987), Viscusi e Hersch (2001), Viscusi e Aldy (2003), Esteves (2008), Fernandez e Nordman (2009), Evans e Schaur (2010) e Contzen, Won e Lavin (2013), sugerem que trabalhadores pertencentes a atividades econômicas com maiores probabilidades de risco de acidentes do trabalho possuem um salário-hora superior aos de trabalhadores de atividades menos arriscadas, mesmo admitindo uma série de controles observáveis individuais, correção de viés de seleção amostral e diferentes modelos econométricos. Na Tabela 3 (ver Apêndice A), estão disponíveis outras especificações de instrumentos e indicadores do ajustamento para o primeiro estágio, cujos valores corroboram as tendências reportadas na Tabela 2 e, em termos globais, qualificam os instrumentos utilizados no que diz respeito à relação entre eles e o Irat.

Quanto à qualidade específica dos instrumentos, a Tabela 4 (ver Apêndice A) mostra diferentes tipos de testes para avaliar o ajustamento da modelagem utilizada: teste de endogeneidade da variável Irat, sobreidentificação e resistência dos instrumentos e teste de identificação de instrumentos fracos. Pelo primeiro teste, verifica-se que a hipótese de exogeneidade para a variável Irat é rejeitada pelos testes de Durbin e Wu-Hausman, tanto para o modelo direcionado a fumantes quanto para os não fumantes. Outra análise realizada é para verificar a existência de sobreidentificação de variáveis instrumentais. De acordo com as estatísticas de Hansen calculadas e dispostas na Tabela 4, no Apêndice A, observa-se que a hipótese de sobreidentificação é rejeitada para os dois modelos (fumantes e não fumantes).

Para um instrumento ter alguma validade, deve ser suficientemente correlacionado com o regressor endógeno, mas não correlacionado com o termo de erro. Na Tabela 4 estão disponíveis estatísticas sobre o poder explicativo dos instrumentos, no bloco de estatísticas relativas à resistência, que constam valores sobre o ajustamento do primeiro estágio do modelo de regressão. $O R^{2}$ ajustado para o caso dos não fumantes foi de $14 \%$, enquanto para os fumantes esse valor foi superior a $10 \%$, sinalizando que as variáveis instrumentais usadas conseguem explicar uma parte da variabilidade do Irat (variável endógena).

Pelo ajustamento do primeiro estágio através do teste $F$, todos os instrumentos apresentam, de forma conjunta, significância estatística ( $p$-valor $=0)$. Por sua vez, o teste de identificação de instrumentos fracos evidencia que os instrumentos são suficientemente confiáveis a pelo menos um viés relativo de 5\% (STOCK; WRIGHT; YOGO, 2002), dado que as estatísticas F de Cragg-Donald e Kleibergen-Paap, para ambos os modelos, são superiores aos valores críticos de Stock e Yogo (2005).

Como previsto no modelo teórico e nos achados empíricos de Viscusi e Hersch (2001), os diferenciais compensatórios requeridos pelos trabalhadores não fumantes são superiores, em qualquer das especificações, aos constatados para os usuários do cigarro. No modelo elaborado para a função condicional média com 
variáveis instrumentais (MQ2E), os não fumantes e os fumantes dispõem, respectivamente, de um coeficiente de 0,152 e 0,10. Já por meio dos estimadores quantílicos, relativamente as maiores diferenças entre os coeficientes para os dois grupos de trabalhadores são verificadas nos quantis 0,10 e 0,75, nos quais as maiores taxas de compensação requerida para ambos os grupos de trabalhadores ocorrem no locus da distribuição acima da mediana $(0,2183$ no quantil 0,75 para os não fumantes e 0,1354 no quantil 0,90 para os fumantes).

Esses resultados se aproximam do trade-off salário-risco exemplificado na Figura 1, para o caso em que $w_{s}<0$ e $w_{p s}<0$, pelos seguintes motivos: através dos resultados da penalização salarial do tabagismo no Brasil, conforme estimações de Almeida e Araújo Júnior (2017), os trabalhadores fumantes recebem uma taxa de salário inferior aos dos não usuários, implicando um efeito negativo do consumo do cigarro sobre os salários no país; e, em termos comparativos, a diferença entre os parâmetros $a_{1}^{f}$ e $a_{1}^{n f}$ é menor do que zero, significando menor prêmio ao risco recebido pelos usuários do cigarro. Com isso, os fumantes tendem a ter uma curva de oferta de trabalho menos inclinada do que a dos não fumantes, de forma que, para um mesmo indicador de atividade perigosa, os fumantes exigem relativamente uma menor compensação salarial. Na linguagem de Hersch e Viscusi (1990), tal resultado representa uma menor aversão revelada ao risco por parte desse grupo de indivíduos. Portanto, os trabalhadores não fumantes escolhem trabalhos mais perigosos se tiverem uma maior compensação de salários, enquanto que os fumantes mostram-se menos avessos ao risco por suportarem os perigos de acidentes do trabalho aceitando um prêmio de risco mais baixo.

Outrossim, a tendência observada pelos coeficientes de diferenciação compensatória salarial ao risco de acidentes por RQVI é, em geral, crescente em relação ao quantil condicional dos rendimentos, tanto para os fumantes quanto para os não fumantes. Logo, trabalhadores situados em quantis mais elevados da distribuição condicional do salário-hora, que propendem a ter maior produtividade do trabalho, exigem uma maior taxa de compensação salarial para atividades com maior periculosidade. Portanto, assim como nos trabalhos de Fernandez e Nordman (2009) e Evans e Schaur (2010), esta pesquisa detecta prêmios ao risco com características heterogêneas dependendo do quantil da distribuição condicional de salários.

Dadas as estimativas para a compensação salarial para o risco de acidentes não fatais, pode-se computar o VSI para o caso brasileiro (ver na Tabela 2) a partir das abordagens de Viscusi e Moore (1987), Viscusi e Hersch (2001) e Viscusi e Aldy (2003). Vale lembrar que o coeficiente de prêmio ao risco estimado corresponde a uma parte do salário relativo que os trabalhadores estão dispostos a aceitar para suportar o risco de uma atividade com chances de acidentes não fatais. Assim, o valor estatístico de um acidente (VSI) é obtido com base nessa interpretação e na média do salário anual previsto para cada grupo de trabalhadores. Na mediana, o VSI para não fumantes é 
de $\mathrm{R} \$ 6.189,38$ e, para os consumidores do cigarro, o VSI é $\mathrm{R} \$ 3.860,76$ por acidente. Quando se verificam os indivíduos mais produtivos (quantis 0,75 e 0,90 ) e que nunca usaram cigarro, o valor estatístico de um acidente é superior a 12 mil reais. Concomitantemente, os trabalhadores localizados abaixo da mediana da distribuição recebem menos de $\mathrm{R} \$ 5,1$ mil. Para os fumantes, os valores estimados pelos quantis mais baixos e mais altos são, na média, a metade do VSI recebido pelo outro grupo. A título de comparação, o VSI estimado por Viscusi (2001) dos fumantes nos Estados Unidos equivale a $44 \%$ do calculado para os não fumantes.

O VSI para o mercado de trabalho norte-americano, medido em dólares do ano 2000, entre os mais de 30 estudos sobre o tema, segundo Viscusi e Aldy (2003), varia no intervalo de US $\$ 20.000$ a US $\$ 70.000$ anuais por acidente, dependendo do método, do período e da variável proxy para o risco de acidente. Restringindo-se para os trabalhos que supõem percepções ao risco variáveis, os fumantes têm prêmios ao risco de acidentes mais baixos do que os não fumantes, correspondentes aos encontrados pela presente pesquisa para o caso brasileiro. Para Viscusi e Hersch (2001), os não fumantes exibem um VSI de US\$ 47.476 e os fumantes de US $\$ 20.755$ - os dois valores atualizados para dólares do ano 2000 -, considerando a covariada do BLS injury rate por 100 trabalhadores e um modelo de regressão condicionado para a média. No confronto direto com o citado trabalho, o VSI estimado para a tendência central da distribuição condicional do salário para o Brasil, medido em dólares de 2000, é consideravelmente inferior ao do caso norte-americano. Além disso, o montante estimado do VSI brasileiro para os quantis mais altos da distribuição condicional de salários, que captam os indivíduos mais produtivos no país, é muito menor do que o calculado por Viscusi e Hersch (2001) entre fumantes e não fumantes com produtividade média nos Estados Unidos.

\section{Considerações Finais}

O objetivo deste trabalho foi verificar como o fato do indivíduo ser fumante afeta o trade-off entre risco e salário. De outra forma, a análise captura como a heterogeneidade de preferências com relação ao risco influencia na compensação de renda necessária para realizar trabalhos com maiores riscos de acidentes de trabalho. A exemplo dos resultados de Hersch e Viscusi (1990) e Viscusi e Hersch (2001), os trabalhadores brasileiros usuários de cigarro recebem relativamente uma menor compensação salarial para atividades insalubres no comparativo com não usuários do produto.

Os resultados mostram que as regressões sem controle de endogeneidade subestimam esse efeito quando comparadas com o modelo com variáveis instrumentais. Com base no RQVI, a estimativa para o valor estatístico de um acidente do trabalho reforça essas diferenças entre os dois grupos, com uma diferença em 
favor dos não usuários do cigarro de, aproximadamente, $R \$ 2,35$ mil e $R \$ 6,78$ mil, respectivamente, nos quantis 0,10 e 0,90 do valor estatístico de um acidente anualizado. Não obstante, o VSI para o caso nacional é muito inferior, por exemplo, ao identificado por Viscusi e Hersch (2001) para o mercado de trabalho dos Estados Unidos, já que comparativamente o valor esperado corresponde a 4,3\% para os não fumantes e a 5,2\% para os fumantes do VSI norte-americano, aumentando, na ordem, para $10,9 \%$ e $14,5 \%$ para os indivíduos brasileiros com maior produtividade marginal condicional.

No contexto atual de redefinição da legislação trabalhista no Brasil, que explícita ou implicitamente envolve a resolução de conflitos entre empregadores e empregados expostos a situações de risco no trabalho, tais resultados podem ser úteis para a formulação de políticas que objetivem preservar a integridade física e psicológica dos trabalhadores atuando em ocupações de risco.

\section{Referências}

ALMEIDA, A. T. C.; ARAÚJO JR., I. T. Tabagismo e Penalização Salarial no Mercado de Trabalho Brasileiro. Economia Aplicada, v. 21, p. 1-31, 2017.

ARNOULD, R. J.; NICHOLS, L. M. Wage-Risk Premiums and Workers' Compensation: A Refinement of Estimates of Compensating Wage Differential. Journal of Political Economy, v. 91, n. 2, p. 332-340, 1983.

BUCHINSKY, M. The dynamics of changes in the female wage distribution in the USA: a quantile regression approach. Journal of Applied Econometrics, v. 13, n. 1, p. 1-30, 1998.

BUCHINSKY, M. Quantile regression with sample selection: Estimating women's return to education in the U.S. Empirical Economics, v. 26, n. 1, p. 87-113, 2001.

CHERNOZHUKOV, V.; HANSEN, C. The Effects of 401(k) Participation on the Wealth Distribution: An Instrumental Quantile Regression Analysis. The Review of Economics and Statistics, v. 86, n. 3, p. 735-751, 2004.

CHERNOZHUKOV, V.; HANSEN, C Notes and comments an IV model of quantile treatment effects. Econometrica, v. 73, n. 1, p. 245-261, 2005.

CHERNOZHUKOV, V.; HANSEN, C Quantile Models with Endogeneity. Annual Review of Economics, v. 5, n. 1, p. 57-81, 2013.

CHERNOZHUKOV, V.; HANSEN, C.; JANSSON, M. Inference approaches for instrumental variable quantile regression. Economics Letters, v. 95, n. 2, p. 272-277, 2007.

CONTZEN, M. P.; WON, A. R.; LAVIN, F. V. The value of a statistical life in Chile. Empirical Economics, v. 45, n. 3, p. 1073-1087, 2013. 
ESTEVES, L. A. Salários e risco de acidentes do trabalho: evidências de diferenciais compensatórios para a indústria manufatureira. Economia Aplicada, v. 12, n. 2, p. 275-287, 2008.

EVANS, M. F.; SCHAUR, G. A quantile estimation approach to identify income and age variation in the value of a statistical life. Journal of Environmental Economics and Management, Elsevier, v. 59, n. 3, p. 260-270, 2010.

FEENSTRA, R. C.; INKLAAR, R.; TIMMER, M. The Next Generation of the Penn World Table. 2013. Disponível em: www.ggdc.net/pwt. Acesso em: 10. nov. 2018.

FERNANDEZ, R. M.; NORDMAN, C. J. Are there pecuniary compensations for working conditions?. Labour Economics, v. 16, n. 2, p. 194-207, 2009.

GALLANT, A. R.; NYCHKA, D. W. Semi-Nonparametric Maximum Likelihood Estimation. Econometrica, v. 55, n. 2, p. 363-390, 1987.

GAREN, J. Compensating Wage Differentials and the Endogeneity of Job Riskiness. The Review of Economics and Statistics, v. 70, n. 1, p. 9-16, 1988.

HERSCH, J. Compensating Differentials for Gender-Specific Job Injury Risks. American Economic Review, v. 88, n. 3, p. 598-607, 1998. 3

HERSCH, J.; VISCUSI, W. K. Cigarette Smoking, Seatbelt Use, and Differences in Wage-Risk Tradeoffs. The Journal of Human Resources, v. 25, n. 2, p. 202-227, 1990.

INSTITUTO BRASILEIRO DE GEOGRAFIA E ESTATÍSTICA. Pesquisa nacional por amostra de domicílios. Rio de Janeiro: IBGE, 2009.

LEVINE, P. B.; GUSTAFSON, T. A.; VELENCHIK, A. D. More bad news for smokers? The effects of cigarette smoking on wages. Industrial and Labor Relations Review, v. 50, n. 3, p. 493-509, 1997.

MINISTÉRIO DA PREVIDÊNCIA SOCIAL. Anuário estatístico de acidentes do trabalho. Brasília: MPS, 2009.

MUNASINGHE, L.; SICHERMAN, N. Why Do Dancers Smoke? Smoking, Time Preference, and Wage Dynamics. Eastern Economic Journal, v. 32, n. 4, p. 595-616, 2006.

POLAT, S. Wage Compensation for Risk: The case of Turkey. GIAM Working Paper No.13-11, n. 13, p. 1-16, 2013.

ROSEN, S. Hedonic Prices and Implicit Markets: Product Differentiation in Pure Competition. Journal of Political Economy, v. 82, n. 1, p. 34-55, 1974.

SCHARFF, R. L.; VISCUSI, W. K. Heterogeneous rates of time preference and the decision to smoke. Economic Inquiry, v. 49, n. 4, p. 959-972, 2011.

SMITH, R. S. Compensating wage differentials and public policy: A review. Industrial and Labor Relations Review, v. 32, n. 3, p. 339-352, 1979. 
STOCK, J. H.; WRIGHT, J. H.; YOGO, M. A Survey of Weak Instruments and Weak Identification in Generalized Method of Moments. Journal of Business 8 Economic Statistics, v. 20, n. 4, p. 518-529, 2002.

STOCK, J. H.; YOGO, M. Testing for Weak Instruments in Linear IV Regression. In: ANDREWS, D.; STOCK, J. H (org.). Identification and Inference for Econometric Models: Essays in Honor of Thomas Rothenberg. Cambridge: Cambridge University Press, 2005.

TIMMINS, C.; MURDOCK, J. A revealed preference approach to the measurement of congestion in travel cost models. Journal of Environmental Economics and Management, v. 53, n. 2, p. 230-249, 2007.

VISCUSI, W. K. Wealth Effects and Earnings Premiums for Job Hazards. The Review of Economics and Statistics, v. 60, n. 3, p. 408-416, 1978.

VISCUSI, W. K.; ALDY, J. E. The Value of a Statistical Life: A Critical Review of Market Estimates Throughout the World. The Journal of Risk and Uncertainty, v. 27, n. 1, p. 5-76, 2003.

VISCUSI, W. K.; HERSCH, J. Cigarette smokers as job risk takers. The Review of Economics and Statistics, v. 83, n. 2, p. 269-280, 2001.

VISCUSI, W. K.; MOORE, M. J. Workers' Compensation: Wage Effects, Benefit Inadequacies, and the Value of Health Losses. The Review of Economics and Statistics, v. 69, n. 2, p. 249-261, 1987.

\section{Apêndice A}

Tabela 3 - Análise de robustez: diferentes especificações de instrumentos

\begin{tabular}{|c|c|c|c|c|c|c|c|c|}
\hline \multirow{3}{*}{ Detalhamento } & \multicolumn{4}{|c|}{ Não fumante } & \multicolumn{4}{|c|}{ Fumante } \\
\hline & \multirow{2}{*}{ MQO } & \multicolumn{3}{|c|}{ VI } & \multirow{2}{*}{ MQO } & \multicolumn{3}{|c|}{ VI } \\
\hline & & $\mathbf{1}$ & 2 & 3 & & $\mathbf{1}$ & 2 & 3 \\
\hline Coeficiente (Irat) & 0,0452 & 0,1655 & 0,1513 & 0,1515 & 0,0225 & 0,0785 & 0,1001 & 0,0996 \\
\hline Erro padrão & 0,0040 & 0,0328 & 0,0122 & 0,0122 & 0,0064 & 0,0052 & 0,0243 & 0,0244 \\
\hline$R^{2}$ ajustado & 0,4616 & 0,4317 & 0,4383 & 0,4414 & 0,4379 & 0,4311 & 0,4249 & 0,4251 \\
\hline \multicolumn{9}{|l|}{ Instrumentos } \\
\hline Casal sem filhos & & $\mathrm{X}$ & $\mathrm{X}$ & $\mathrm{X}$ & & $\mathrm{X}$ & $\mathrm{X}$ & $\mathrm{X}$ \\
\hline Casal com filhos & & $\mathrm{x}$ & $\mathrm{X}$ & $\mathrm{X}$ & & $\mathrm{X}$ & $\mathrm{X}$ & $\mathrm{x}$ \\
\hline Chefe do domicílio & & & $\mathrm{X}$ & $\mathrm{X}$ & & $\mathrm{X}$ & $\mathrm{X}$ & $\mathrm{X}$ \\
\hline Renda de não trabalho & & & $\mathrm{X}$ & $\mathrm{X}$ & & & $\mathrm{X}$ & $\mathrm{X}$ \\
\hline Esposa com dificuldades físicas & & & & $\mathrm{X}$ & & & & $\mathrm{X}$ \\
\hline Filho com dificuldades físicas & & & & $\mathrm{x}$ & & & & $\mathrm{X}$ \\
\hline Atributos individuais & $\mathrm{X}$ & $\mathrm{X}$ & $\mathrm{X}$ & $\mathrm{X}$ & $\mathrm{X}$ & $\mathrm{x}$ & $\mathrm{X}$ & $\mathrm{x}$ \\
\hline Fatores locacionais & $\mathrm{X}$ & $\mathrm{X}$ & $\mathrm{X}$ & $\mathrm{X}$ & $\mathrm{X}$ & $\mathrm{X}$ & $\mathrm{X}$ & $\mathrm{X}$ \\
\hline Controle: ex-fumantes & $\mathrm{X}$ & $\mathrm{X}$ & $\mathrm{X}$ & $\mathrm{X}$ & $\mathrm{X}$ & $\mathrm{X}$ & $\mathrm{X}$ & $\mathrm{X}$ \\
\hline
\end{tabular}

Continua... 
Conclusão.

\begin{tabular}{|c|c|c|c|c|c|c|c|c|}
\hline \multirow{3}{*}{ Detalhamento } & \multicolumn{4}{|c|}{ Não fumante } & \multicolumn{4}{|c|}{ Fumante } \\
\hline & \multirow{2}{*}{ MQO } & \multicolumn{3}{|c|}{ VI } & \multirow{2}{*}{ MQO } & \multicolumn{3}{|c|}{ VI } \\
\hline & & $\mathbf{1}$ & 2 & 3 & & $\mathbf{1}$ & 2 & 3 \\
\hline Número de observações & 22.088 & 22.088 & 22.088 & 22.088 & 8.153 & 8.153 & 8.153 & 8.153 \\
\hline \multicolumn{9}{|l|}{$\begin{array}{l}\text { Resistência dos instru- } \\
\text { mentos }\end{array}$} \\
\hline \multicolumn{9}{|l|}{$\begin{array}{l}\text { Ajustamento do primeiro } \\
\text { estágio }\end{array}$} \\
\hline$R^{2}$ ajustado & & 0,1192 & 0,1405 & 0,1407 & & 0,0868 & 0,1064 & 0,1062 \\
\hline$R^{2}$ parcial & & 0,0938 & 0,0967 & 0,0971 & & 0,0723 & 0,0774 & 0,0664 \\
\hline Estatística-F & & 1129,91 & 1144,91 & 654,93 & & 498,14 & 377,98 & 198,69 \\
\hline$P$-valor $(F)$ & & 0,0000 & 0,0000 & 0,0000 & & 0,0000 & 0,0000 & 0,0000 \\
\hline
\end{tabular}

Fonte: Elaboração própria a partir dos microdados da PNAD/PETab 2008 e do AEAT/MPS 2008.

Tabela 4 - Testes de endogeneidade e validade dos instrumentos para o modelo VI (3) de não fumantes e fumantes

\begin{tabular}{|c|c|c|c|c|}
\hline \multirow[b]{2}{*}{ Testes } & \multicolumn{2}{|c|}{ Não fumante } & \multicolumn{2}{|l|}{ Fumante } \\
\hline & Estatística & p-valor & Estatística & p-valor \\
\hline \multicolumn{5}{|l|}{ Endogeneidade (Ho: variável exógena) } \\
\hline Escore robusto (Durbin) $\chi_{1}^{2}$ & 102,96 & 0,0000 & 82,882 & 0,0000 \\
\hline Regressão robusta (Wu-Hausman) F & 84,39 & 0,0000 & 70,7428 & 0,0000 \\
\hline \multicolumn{5}{|l|}{ Restrição de sobreidentificação } \\
\hline $\begin{array}{l}\text { Escore } \chi_{(6)}^{2} \text { (estatística de Hansen de todos os } \\
\text { instrumentos) }\end{array}$ & 130,101 & 0,0000 & 102,518 & 0,0000 \\
\hline \multicolumn{5}{|l|}{ Resistência dos instrumentos } \\
\hline \multicolumn{5}{|l|}{ Ajustamento do primeiro estágio } \\
\hline$R^{2}$ ajustado & 0,1407 & & 0,1062 & \\
\hline$R^{2}$ parcial & 0,0971 & & 0,0664 & \\
\hline$F$ robusto & 654,93 & 0,0000 & 198,69 & 0,0000 \\
\hline \multicolumn{5}{|l|}{ Teste de identificação de instrumentos fracos } \\
\hline Cragg-Donald (estatística F de Wald) & 82,626 & & 338,984 & \\
\hline Kleibergen-Paap (estatística $F$ de Wald) & 198,687 & & 654,925 & \\
\hline \multicolumn{5}{|l|}{ Valores críticos do teste de Stock e Yogo (2005) } \\
\hline - Viés relativo máximo de 5\% & 19,86 & & 19,86 & \\
\hline - Viés relativo máximo de 10\% & 11,29 & & 11,29 & \\
\hline - Viés relativo máximo de 20\% & 6,73 & & 6,73 & \\
\hline - Viés relativo máximo de 30\% & 5,07 & & 5,07 & \\
\hline
\end{tabular}

Fonte: Elaboração própria a partir dos microdados da PNAD/PETab 2008 e do AEAT/MPS 2008 . 
Quadro 1 - Definição das variáveis usadas na pesquisa por tipo de modelo

\begin{tabular}{|c|c|c|c|c|}
\hline \multirow{2}{*}{ Variáveis } & \multirow{2}{*}{ Descrição das variáveis } & \multicolumn{3}{|c|}{ Modelos } \\
\hline & & $M$ & $l$ & VI \\
\hline Salário-hora & $\begin{array}{l}\text { Renda do trabalho principal na semana de referência por } \\
\text { horas trabalhadas (em log). }\end{array}$ & $\mathrm{X}$ & & \\
\hline Irat & $\begin{array}{l}\text { Índice de risco de acidentes do trabalho na divisão } \\
\text { econômica por } 100 \text { trabalhadores. }\end{array}$ & $\mathrm{X}$ & & \\
\hline $\begin{array}{l}\text { Participação na força de } \\
\text { trabalho }\end{array}$ & $\begin{array}{l}\text { Um se o indivíduo possui rendimentos positivos e não } \\
\text { nulos, zero caso contrário. }\end{array}$ & & $\mathrm{X}$ & \\
\hline Carteira assinada & $\begin{array}{l}\text { Um se o trabalhador está exercendo atividade com } \\
\text { carteira assinada, zero caso contrário. }\end{array}$ & $\mathrm{X}$ & & \\
\hline Sindicalizado & Um se o trabalhador é sindicalizado, zero caso contrário. & $\mathrm{X}$ & & \\
\hline Dirigentes & $\begin{array}{l}\text { Um se dirigentes em geral no trabalho principal, zero caso } \\
\text { contrário. }\end{array}$ & $\mathrm{X}$ & & \\
\hline Ciências e Artes & $\begin{array}{l}\text { Um se profissionais das ciências e das artes, zero caso } \\
\text { contrário. }\end{array}$ & $\mathrm{x}$ & & \\
\hline Técnicos & Um se técnicos de nível médio, zero caso contrário. & $\mathrm{X}$ & & \\
\hline Serviços administrativos & $\begin{array}{l}\text { Um se trabalhadores de serviços administrativos, zero caso } \\
\text { contrário. }\end{array}$ & $\mathrm{X}$ & & \\
\hline Serviços* & Um se trabalhadores dos serviços, zero caso contrário. & $\mathrm{X}$ & & \\
\hline Vendedores & $\begin{array}{l}\text { Um se vendedores e prestadores de serviço do comércio, } \\
\text { zero caso contrário. }\end{array}$ & $\mathrm{X}$ & & \\
\hline Agrícola & Um se trabalhadores agrícolas, zero caso contrário. & $\mathrm{X}$ & & \\
\hline Produção e manutenção & $\begin{array}{l}\text { Um se trabalhadores da produção de bens e serviços e de } \\
\text { reparação e manutenção, zero caso contrário. }\end{array}$ & $\mathrm{X}$ & & \\
\hline Estabilidade (tenure) & Tempo de serviço em anos no emprego atual. & $\mathrm{X}$ & & \\
\hline$<\mathrm{EF}$ & $\begin{array}{l}\text { Um se menos que ensino fundamental completo, zero } \\
\text { caso contrário. }\end{array}$ & $\mathrm{X}$ & $\mathrm{X}$ & \\
\hline $\mathrm{EF}$ & $\begin{array}{l}\text { Um se ensino fundamental completo ou médio } \\
\text { incompleto, zero caso contrário. }\end{array}$ & $\mathrm{x}$ & $\mathrm{x}$ & \\
\hline EM & $\begin{array}{l}\text { Um se ensino médio completo ou superior incompleto, } \\
\text { zero caso contrário. }\end{array}$ & $\mathrm{X}$ & $\mathrm{X}$ & \\
\hline$E S^{*}$ & $\begin{array}{l}\text { Um se ensino superior completo ou mais anos de estudo, } \\
\text { zero caso contrário. }\end{array}$ & $\mathrm{X}$ & $\mathrm{X}$ & \\
\hline Raça & Um se o trabalhador é da cor branca, zero caso contrário. & $\mathrm{X}$ & $\mathrm{X}$ & \\
\hline Idade & Idade em anos. & $\mathrm{X}$ & $\mathrm{X}$ & \\
\hline Fumante & Um se o trabalhador é fumante, zero caso contrário. & $\mathrm{X}$ & & \\
\hline Tamanho da família & $\begin{array}{l}\text { Componentes da família (excluindo-se pensionista, } \\
\text { empregado doméstico ou parente do empregado). }\end{array}$ & & $\mathrm{X}$ & \\
\hline Dificuldades físicas & \begin{tabular}{|l|l|} 
Um se tem dificuldade para levantar objetos, praticar \\
esportes ou realizar trabalhos pesados; zero caso contrário.
\end{tabular} & & $\mathrm{X}$ & \\
\hline Aposentadoria & $\begin{array}{l}\text { Renda com aposentadoria de instituto de previdência ou } \\
\text { do governo federal, ou outro tipo (em log). }\end{array}$ & & $\mathrm{X}$ & \\
\hline Pensão & $\begin{array}{l}\text { Renda com pensão de instituto de previdência ou do } \\
\text { governo federal, ou outro tipo (em log). }\end{array}$ & & $\mathrm{X}$ & \\
\hline Aluguel & Rendimento de aluguel (em log). & & $\mathrm{X}$ & \\
\hline Outros & $\begin{array}{l}\text { Renda com juros, dividendos, programas sociais ou outros } \\
\text { rendimentos, abono ou doação (em log). }\end{array}$ & & $\mathrm{X}$ & \\
\hline
\end{tabular}

Continua... 
Conclusão.

\begin{tabular}{|c|c|c|c|c|}
\hline Chefe do domicilio & $\begin{array}{l}\text { Um se o indivíduo é o morador de referência do } \\
\text { domicílio, zero caso contrário. }\end{array}$ & & $\mathrm{X}$ & \\
\hline Casado sem filhos & $\begin{array}{l}\text { Um se a pessoa é casada, mas sem filhos; zero caso } \\
\text { contrário. }\end{array}$ & & $\mathrm{X}$ & \\
\hline Casado com filhos & $\begin{array}{l}\text { Um se a pessoa é casada, mas com filhos; zero caso } \\
\text { contrário. }\end{array}$ & & $X$ & \\
\hline Urbana & $\begin{array}{l}\text { Um se o indivíduo reside em área urbana, zero caso } \\
\text { contrário. }\end{array}$ & $\mathrm{X}$ & $X$ & \\
\hline Região metropolitana & $\begin{array}{l}\text { Um se o indivíduo reside em região metropolitana, zero } \\
\text { caso contrário. }\end{array}$ & $\mathrm{X}$ & $\mathrm{X}$ & \\
\hline Norte & $\begin{array}{l}\text { Um se o indivíduo reside na região Norte, zero caso } \\
\text { contrário. }\end{array}$ & $\mathrm{X}$ & $\mathrm{X}$ & \\
\hline Nordeste & $\begin{array}{l}\text { Um se o indivíduo reside na região Nordeste, zero caso } \\
\text { contrário. }\end{array}$ & $\mathrm{X}$ & $X$ & \\
\hline Sudeste & $\begin{array}{l}\text { Um se o indivíduo reside na região Sudeste, zero caso } \\
\text { contrário. }\end{array}$ & $\mathrm{X}$ & $\mathrm{X}$ & \\
\hline Sul & $\begin{array}{l}\text { Um se o indivíduo reside na região Sul, zero caso } \\
\text { contrário. }\end{array}$ & $\mathrm{X}$ & $\mathrm{X}$ & \\
\hline Centro-Oeste & $\begin{array}{l}\text { Um se o indivíduo reside na região Centro-Oeste, zero } \\
\text { caso contrário. }\end{array}$ & $\mathrm{X}$ & $\mathrm{X}$ & \\
\hline Chefe do domicilio & $\begin{array}{l}\text { Um se o indivíduo é o morador de referência do } \\
\text { domicílio, zero caso contrário. }\end{array}$ & & $\mathrm{X}$ & $\mathrm{X}$ \\
\hline Casado sem filhos & $\begin{array}{l}\text { Um se a pessoa é casada, mas sem filhos; zero caso } \\
\text { contrário. }\end{array}$ & & $\mathrm{X}$ & $\mathrm{X}$ \\
\hline Casado com filhos & $\begin{array}{l}\text { Um se a pessoa é casada, mas com filhos; zero caso } \\
\text { contrário. }\end{array}$ & & $\mathrm{X}$ & $\mathrm{X}$ \\
\hline Renda total do não trabalho & $\begin{array}{l}\text { Rendimento total de outras fontes não ligadas ao trabalho } \\
\text { atual (em log). }\end{array}$ & & & $\mathrm{X}$ \\
\hline Cônjuge: dificuldades físicas & $\begin{array}{l}\text { Um se a cônjuge possui dificuldades físicas (tal como } \\
\text { descrito acima); zero caso contrário. }\end{array}$ & & & $\mathrm{X}$ \\
\hline Filho: dificuldades físicas & $\begin{array}{l}\text { Um se o filho do indivíduo tem dificuldades físicas (tal } \\
\text { como descrito acima); zero caso contrário. }\end{array}$ & & & $\mathrm{X}$ \\
\hline
\end{tabular}

Fonte: Elaboração própria.

Notas: A coluna $M$ representa as variáveis utilizadas para as equações de rendimento; a coluna l indica as variáveis usadas para a correção do viés de seleção amostral; a coluna VI reporta a descrição das variáveis instrumentais adotadas para os modelos MQ2E e RQVI em M.

\section{Autor correspondente:}

Ignácio Tavares Araújo Júnior

Recebido em: 12/03/2019.

E-mail: ignacio@ccsa.ufpb.br

Aceito em: 18/03/2020. 


\section{(cc) BY}

Este é um artigo de acesso aberto distribuído sob os termos da Creative Commons Attribution CC-BY 4.0, que permite uso irrestrito, distribuição e reprodução em qualquer meio, desde que o trabalho original seja devidamente citado. 